\title{
Successful multidisciplinary treatment of hilar cholangiocarcinoma in a patient with complicated new-onset coronary artery disease
}

\author{
Takahisa Fujikawa, Akira Tanaka
}

Department of Surgery, Kokura Memorial Hospital, Kitakyushu, Japan

Correspondence to Dr Takahisa Fujikawa, fujikawa-t@kokurakinen.or.jp

Accepted 25 March 2014

\section{SUMMARY}

We report a 69-year-old man suffering from hilar cholangiocarcinoma and concurrent new-onset complicated coronary artery disease. After implanting non-drug-eluting coronary stents, combination chemotherapy with gemcitabine and S-1 under continuation of dual antiplatelet therapy was carried out and partial tumour response was achieved. Subsequently, extended right hepatectomy with partial resection of the Spiegel lobe and left hepaticojejunostomy was performed while continuing preoperative single antiplatelet therapy with aspirin. The patient recovered well without any thromboembolic or bleeding complications. Like the current case, neoadjuvant chemotherapy and subsequent curative resection under continuation of antiplatelet therapy, followed by preceding coronary intervention, is one of the preferred options for the treatment of hepatobiliary malignancy in patients with concurrent new-onset coronary artery disease.

\section{BACKGROUND}

In non-cardiac surgery patients receiving antiplatelet therapy, especially in patients with recent coronary stent implantation (CSI), perioperative management is challenging due to increased risks of perioperative bleeding or thromboembolic complications. ${ }^{1-3}$ We have to balance perioperative risks (bleeding and/or thromboembolism) against oncological risks and benefits to make a decision. We report a case of concurrent locally advanced hilar cholangiocarcinoma and new-onset complicated coronary artery disease successfully treated by combination of preceding coronary stent implantation, neoadjuvant chemotherapy and aggressive surgical resection under rigorous perioperative antithrombotic management.

\section{CASE PRESENTATION}

A 69-year-old Japanese man was admitted to a hospital for progressive jaundice. He was diagnosed with locally advanced hilar cholangiocarcinoma infiltrating the right hepatic duct and gallbladder (Bismuth-Corlette type IIIa) ${ }^{4}$ without any distant metastasis by enhanced CT scan and endoscopic retrograde cholangiogram (figure 1A,B). Prior to surgical resection, portal vein embolisation was attempted to gain sufficient remnant hepatic volume. During embolisation of the right anterior portal branch, the patient developed ventricular fibrillation arrest, which was successfully resuscitated. $\mathrm{He}$ was transferred to our hospital for further assessment and management. Coronary angiography was performed and revealed significant stenotic lesions in the left anterior descending and circumflex branches.

\section{TREATMENT}

Surgeons and gastroenterologists discussed together with cardiologists how best to manage the concurrent status of having both locally advanced hilar cholangiocarcinoma and unstable coronary artery disease. Considering the balance between operative risks and oncological risk/benefit, preceding CSI with 'non-drug-eluting' coronary stents, endoscopic placement of internal biliary stent and the following neoadjuvant chemotherapy with continuation of dual antiplatelet therapy (DAPT) for a couple of months, and subsequent possible surgical resection were scheduled. The patient was informed regarding risks, benefits and alternative therapeutic modalities, who agreed with the strategy.

After implantation of non-drug-eluting coronary stents into both his left anterior descending and circumflex arteries, DAPT with clopidogrel and aspirin was started. Subsequently, combination chemotherapy with gemcitabine $\left(1000 \mathrm{mg} / \mathrm{m}^{2}\right.$, days 1 and 8$)$ and S-1 $\left(80 \mathrm{mg} / \mathrm{m}^{2}\right.$, days $\left.1-14\right)$ was introduced, and seven cycles were carried out without any significant adverse drug events. The tumour response was assessed as partial response according to the Response Evaluation Criteria in Solid Tumours 1.0 criteria, and the status of biliary obstruction was remarkably improved (figure 1C,D).

Six months after the first manifestation, a surgical intervention was attempted. Preoperative antithrombotic management consisted of discontinuation of DAPT 7 days prior to surgery and continuation of single antiplatelet therapy with aspirin until surgery. Intraoperative exploration revealed the hilar mass locating mainly in the right hepatic duct and involving the right liver and gallbladder, but not invading the left hepatic artery or portal vain. Owing to possible antiplatelet-induced bleeding tendency, meticulous dissection and haemostasis were performed using coagulating shears and monopolar dissecting sealers. Extended right hepatectomy with partial resection of the Spiegel lobe and left hepaticojejunostomy was carried out without experiencing any intractable bleeding. Postoperative management was introduced in the intensive care unit, without any immediate critical complications.

The surgical specimen macroscopically demonstrated a $2 \mathrm{~cm}$ sized undemarcated hilar mass 
Figure 1 (A) Enhanced $\mathrm{CT}$ of the abdomen revealed undemarcated mass at the hilum of the liver, invading the right liver and the gallbladder (dotted area, also shown as arrows in the coronal image). (B) Endoscopic retrograde cholangiography showed complete obstruction of the right and left hepatic ducts (arrows). (C and D) After seven cycles of combination chemotherapy with gemcitabine and S-1 under continuation of dual antiplatelet therapy, the tumour was reduced in size and the status of biliary obstruction was remarkably improved (dotted area of the axial CT scan in (C), arrows of drip-infusion cholangiography CT scan in (D)).
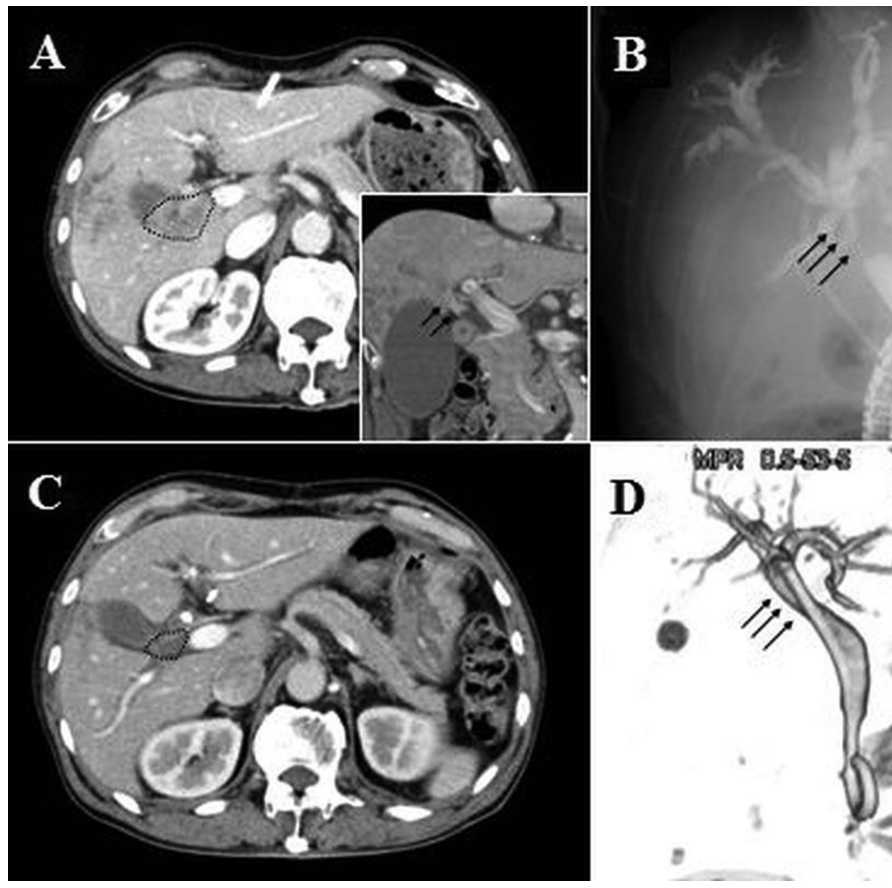

invading the liver parenchyma and the gallbladder. Pathological examination indicated the presence of islands of residual grade IIa moderately differentiated tubular adenocarcinoma with some degree of perineural invasion, surrounded by lymphocytic infiltrate and dense fibrous stroma indicating a chemotherapeutic effect. The surgical margin was negative for malignancy.

\section{OUTCOME AND FOLLOW-UP}

The patient recovered soon postoperatively without any thromboembolic or bleeding complications. His antiplatelet therapy was reinstituted in stages; aspirin was restarted on postoperative day (POD) 3 and clopidogrel on POD4. He developed bile leakage postoperatively, which was conservatively managed and relieved.

Although postoperative adjuvant chemotherapy with gemcitabine $\left(1000 \mathrm{mg} / \mathrm{m}^{2}\right)$ was continued, he developed carcinomatous pleurisy with massive right pleural effusion 20 months after the operation, which was treated by chest drainage and low-dose intrathoracic cisplatin infusion ( $20 \mathrm{mg} /$ body $)$. Subsequently, combination chemotherapy with cisplatin $\left(25 \mathrm{mg} / \mathrm{m}^{2}\right)$ and gemcitabine $\left(1000 \mathrm{mg} / \mathrm{m}^{2}\right)$ was introduced and continued. He remained doing well with stable cancer condition 36 months after the original diagnosis was made.

\section{DISCUSSION}

The current case involved a dilemma of how to treat two different critical diseases; locally advanced hilar cholangiocarcinoma and concurrent new-onset coronary artery disease. If a patient had just experienced unstable coronary artery disease like our case, CSI before abdominal surgery would be preferable but long-term strong DAPT is required after CSI, especially after drug-eluting stent implantation. For this reason, surgical procedures performed early after CSI are associated with significantly high risks of both thromboembolic and bleeding complications. ${ }^{5-7}$

Additionally, major hepatobiliary surgery for malignancy is one of the most difficult abdominal procedures and is associated with major intraoperative and postoperative bleeding complications. ${ }^{8} 9$ It is reasonable to delay such a major surgery for a couple of months after CSI. On the other hand, surgical resection for hilar cholangiocarcinoma is the only curative treatment and patients sometimes become incurable due to the delay in surgery. In the current case, according to the strategy finally made by surgeons, gastroenterologists and cardiologists, preceding CSI with 'non-drug-eluting' coronary stent implantation, endoscopic placement of internal biliary stent and the following neoadjuvant chemotherapy with continuation of DAPT, and subsequent curative surgical resection of hilar cholangiocarcinoma were successfully performed.

Perioperative antithrombotic management is also challenging and often troublesome in antiplatelet-burdened patients receiving major hepatobiliary surgery for malignancy. The potential risk of vessel or stent thrombosis may increase when antiplatelet is stopped perioperatively; surgical haemorrhage or postoperative bleeding complications may occur more often when antiplatelet is continued before the operation. ${ }^{2} 510$ Not only meticulous intraoperative dissection and haemostasis using various haemostatic devices, but also rigorous assessment and perioperative antithrombotic management is warranted in such a complicated situation. We have previously demonstrated

\section{Learning points}

- Patients with new-onset coronary artery disease who need to undergo major hepatobiliary surgery for malignancy are at extremely high risks of bleeding and thromboembolic complications.

- Neoadjuvant chemotherapy and subsequent curative resection under continuation of antiplatelet therapy, followed by preceding coronary intervention, is a preferred option for the treatment of hepatobiliary malignancy in patients with new-onset coronary artery disease.

- In this situation, rigorous assessment and perioperative management, as well as meticulous intraoperative dissection and haemostasis are necessary to achieve successful outcomes. 
feasibility and safety of abdominal operations under preoperative continuation of single antiplatelet therapy with aspirin in the case of patients with high-thromboembolic risks.10 In the present case, extended right hepatectomy and biliary reconstruction were also safely and satisfactorily performed without any perioperative bleeding or thromboembolic complications under continuation of aspirin monotherapy.

In summary, we report a 69-year-old man suffering from hilar cholangiocarcinoma and concurrent new-onset coronary artery disease. Neoadjuvant chemotherapy and subsequent curative resection under continuation of antiplatelet therapy, followed by preceding coronary intervention, is one of the preferred options for the treatment of such a complicated case.

Contributors TF operated and managed the patients perioperatively. TF prepared the manuscript. AT reviewed the manuscript.

Competing interests None.

Patient consent Obtained.

Provenance and peer review Not commissioned; externally peer reviewed.

\section{REFERENCES}

1 Fujikawa T, Maekawa H, Shiraishi K, et al. Successful resection of complicated bleeding arteriovenous malformation of the jejunum in patients starting dual-antiplatelet therapy just after implanting a drug-eluting coronary stent. BMJ Case Rep 2012;2012:pii: bcr2012006779.

2 Fujikawa T, Noda T, Tada S, et al. Intractable intraoperative bleeding requiring platelet transfusion during emergent cholecystectomy in a patient with dual antiplatelet therapy after drug-eluting coronary stent implantation (with video). BMJ Case Rep 2013;2013:pii: bcr2013008948.

3 Thachil J, Gatt A, Martlew V. Management of surgical patients receiving anticoagulation and antiplatelet agents. Br J Surg 2008;95:1437-48.

4 Bismuth H, Corlette MB. Intrahepatic cholangioenteric anastomosis in carcinoma of the hilus of the liver. Surg Gynecol Obstet 1975;140:170-8.

5 Kaluza GL, Joseph J, Lee JR, et al. Catastrophic outcomes of noncardiac surgery soon after coronary stenting. J Am Coll Cardiol 2000;35:1288-94.

6 Kimura T, Isshiki T, Hayashi Y, et al. Incidence and outcome of surgical procedures after sirolimus-eluting stent implantation: a report from the j-Cypher registry. Cardiovasc Interv Ther 2011;25:29-39.

7 Schouten 0 , van Domburg RT, Bax JJ, et al. Noncardiac surgery after coronary stenting: early surgery and interruption of antiplatelet therapy are associated with an increase in major adverse cardiac events. J Am Coll Cardiol 2007:49:22-124.

8 Dinant $S$, Gerhards MF, Rauws EA, et al. Improved outcome of resection of hilar cholangiocarcinoma (Klatskin tumor). Ann Surg Oncol 2006;13:872-80.

9 Nagino M, Ebata T, Yokoyama Y, et al. Evolution of surgical treatment for perihilar cholangiocarcinoma: a single-center 34-year review of 574 consecutive resections. Ann Surg 2013;258:129-40.

10 Fujikawa T, Tanaka A, Abe T, et al. Does antiplatelet therapy affect outcomes of patients receiving abdominal laparoscopic surgery? Lessons from more than 1,000 laparoscopic operations in a single tertiary referral hospital. J Am Coll Surg 2013;217:1044-53.

Copyright 2014 BMJ Publishing Group. All rights reserved. For permission to reuse any of this content visit

http://group.bmj.com/group/rights-licensing/permissions.

BMJ Case Report Fellows may re-use this article for personal use and teaching without any further permission.

Become a Fellow of BMJ Case Reports today and you can:

- Submit as many cases as you like

- Enjoy fast sympathetic peer review and rapid publication of accepted articles

- Access all the published articles

- Re-use any of the published material for personal use and teaching without further permission

For information on Institutional Fellowships contact consortiasales@bmjgroup.com

Visit casereports.bmj.com for more articles like this and to become a Fellow 